\title{
Duplications at 19q13.33 in patients with neurodevelopmental disorders
}

Eduardo Pérez-Palma, PhD, Elmo Saarentaus, MD, Marie Ravoet, PhD, Giancarlo V. De Ferrari, PhD, Peter Nürnberg, PhD, Bertrand Isidor, MD, PhD, Bernd A. Neubauer, MD, and Dennis Lal, PhD

Neurol Genet 2018;4:e210. doi:10.1212/NXG.0000000000000210

\section{Abstract}

\section{Objective}

After the recent publication of the first patients with disease-associated missense variants in the GRIN2D gene, we evaluate the effect of copy number variants (CNVs) overlapping this gene toward the presentation of neurodevelopmental disorders (NDDs).

\section{Methods}

We explored ClinVar (number of CNVs = 50,794) and DECIPHER (number of CNVs $=28,085$ ) clinical databases of genomic variations for patients with copy number changes overlapping the GRIN2D gene at the 19q13.33 locus and evaluated their respective phenotype alongside their frequency, gene content, and expression, with publicly available reference databases.

\section{Results}

We identified 11 patients with microduplications at the $19 q 13.33$ locus. The majority of CNVs arose de novo, and comparable CNVs are not present in control databases. All patients were reported to have NDDs and dysmorphic features as the most common clinical phenotype $(\mathrm{N}=$ $8 / 11)$, followed by seizures $(\mathrm{N}=6 / 11)$ and intellectual disability $(\mathrm{N}=5 / 11)$. All duplications shared a consensus region of $405 \mathrm{~kb}$ overlapping 13 genes. After screening for duplication tolerance in control populations, positive gene brain expression, and gene dosage sensitivity analysis, we highlight 4 genes for future evaluation: CARD8, C19orf68, KDELR1, and GRIN2D, which are promising candidates for disease causality. Furthermore, investigation of the literature especially supports GRIN2D as the best candidate gene.

\section{Conclusions}

Our study presents dup19q13.33 as a novel duplication syndrome locus associated with NDDs. CARD8, C19orf68, KDELR1, and GRIN2D are promising candidates for functional follow-up.

\author{
Correspondence \\ Dr. Lal \\ dlal@broadinstitute.org
}




\section{Glossary}

DD = developmental delay; ID = intellectual disability; LoF = loss of function; NDD = neurodevelopmental disorder.

NMDA receptors are involved in neurodevelopmental processes such as synaptogenesis, learning, and memory. Structurally, NMDA receptors are composed of 2 subunits of GluN1 and GluN2, which are specifically encoded by the GRIN1 and GRIN2A to GRIN2D genes, respectively. ${ }^{1}$ While single nucleotide and copy number variants (CNVs) in the NMDA receptor subunits GRIN1, GRIN2A, and GRIN2B have been associated with a range of neurodevelopmental disorders (NDDs), little is known about the association of GRIN2D variants and NDDs. Recently, de novo missense mutations in GRIN2D (p.Val667Ile) have been identified as the cause of severe epileptic encephalopathy ${ }^{2}$ in 2 independent patients. However, whether CNVs covering the GRIN2D locus are also associated with disease has not been studied. GRIN2D is encoded at the end of the long arm of chromosome 19 at the 19q13.33 locus. We hypothesize that dosage changes in GRIN2D are highly likely to be disease associated based on the high sequence homology, expression during neurodevelopment, and a functional relationship with the established diseaseassociated paralogous genes.

\section{Methods}

\section{Standard protocol approvals, registrations, and patient consents}

We obtained approval from an ethical standards committee on human experimentation (institutional or regional) for any experiments using human subjects. Written informed consent was obtained from all patients (or guardians of patients) participating in the study (consent for research), following the guidelines provided by ClinVar and DECHIPER databases. We obtained authorization for disclosure (consent to disclose) of the photograph that may be published in the journal, in derivative works by the AAN, or on the journal's website.

\section{Data analysis}

Using the gene-oriented query "GRIN2D," we accessed 2 publicly available repositories of clinical genetic variation: (1) The Database of Chromosomal Imbalance and Phenotype in Humans using Ensembl Resources, DECIPHER ${ }^{3}$ (URL: https://decipher.sanger.ac.uk, accessed on July 2016) and (2) The public archive of interpretations of clinically relevant variants, ClinVar ${ }^{4}$ (URL: http://www.ncbi.nlm.nih.gov/clinvar, accessed on July 2016). For DECIPHER patients, the individual scientists were contacted to acquire further phenotype information including the presence of intellectual disability (ID), developmental delay (DD), seizures, hypotonia, dysmorphism (Dysm), learning difficulties, behavioral problems as well as social communication, and behavioral disorders of the autism spectrum disorder. ${ }^{5}$ We considered only DECIPHER entries with positive submitter contact. All phenotypes evaluated were considered as binary denominators (i.e., Yes/No). Gene annotations of the extracted CNVs refer to the genome build GRCh37/hg19. A consensus region was determined with an inhouse Python script (available on request). Genes inside the consensus region were further evaluated as disease candidate genes with additional publicly available resources for (1) brain expression, strongly brain-expressed genes $(n=4,756)$, specified by a log (RPKM) $>4.5$ of the BrainSpan RNA.Seq transcriptome data $\operatorname{set}^{6} ;(2)$ overlapping CNVs reported in the curated control inclusive map of the Database of Genomic Variants ${ }^{7}$; (3) loss-of-function (LoF) intolerance reported in the Exome Aggregation Consortium, ${ }^{8}$ given by a probability of being LoF intolerant (pLI score) equal to or greater than 0.9 based on the observed genetic variation of 60,706 healthy individuals; and (4) overlapping CNVs reported in 20,227 controls. ${ }^{9}$ Genome-wide brain-specific noncoding functional elements were extracted from the GenoSkyline; project (http://genocanyon.med.yale.edu/GenoSkyline), which implements a statistical framework based on high-throughput genetic and epigenetic data to predict tissue-specific functional noncoding elements. ${ }^{10}$

\section{Results}

We detected 11 patients with CNVs overlapping the 19q13.33 locus (table 1). Of interest, all of them were duplications. Three were annotated in ClinVar (patients 1 through 3) and 8 in DECIPHER (patients 4 through 11). Although a ninth individual did fulfill the inclusion criteria (DECIPHER entry 275388), given the actual size of the reported variant in comparison with the entire chromosome $19(\mathrm{CNV}=58.83 \mathrm{Mb}$ vs $\mathrm{Chr} 19=59.12 \mathrm{Mb}$ ), it was considered a chromosome trisomy and therefore was excluded. Detailed clinical phenotypes are provided in table 1 . Notably, all patients were reported to have mild to severe forms of NDDs. Of all the phenotypes evaluated, mild but distinct dysmorphic features were the most frequent $(n=8)$, followed by seizures $(n=6$, including generalized tonic and febrile seizures), ID $(n=5)$, and DD $(n=4)$. In particular, dysmorphisms were present in patients carrying CNVs larger than $3 \mathrm{Mb}$ (pathogenic size according to the American College of Human Genetics). The image of 1 of such patients is shown in figure, A, showing a child with signs of macrostomia, midface hypoplasia, and progenia.

For DECIPHER entries with available parental information, $85.7 \%(n=6)$ of observed microduplications were de novo, and only 1 was inherited from an affected family member. The majority of $(87.5 \%, \mathrm{n}=7)$ patients did not carry additional CNVs, and none of the additional CNVs found in 3 patients covered a known disease locus or known disease 
Table 1 Clinical phenotypes of the 11 retrieved patients with GRIN2D variants at the 19q13.33 locus

\begin{tabular}{|c|c|c|c|c|c|c|c|c|c|c|c|c|c|c|c|}
\hline Patient & Resource & $\begin{array}{l}\text { Database entry } \\
\text { ID }\end{array}$ & $\begin{array}{l}\text { Size } \\
(M b)\end{array}$ & Sex & $\begin{array}{l}\text { Type of } \\
\text { variant }\end{array}$ & $\begin{array}{l}\text { De } \\
\text { novo }\end{array}$ & $\begin{array}{l}\text { No } \\
\text { CNVs }\end{array}$ & ID & DD & Seizures & Hypotonia & ASD & Dysm & $\begin{array}{l}\text { Learning } \\
\text { difficulties }\end{array}$ & $\begin{array}{l}\text { Behavioral } \\
\text { problems }\end{array}$ \\
\hline 1 & ClinVar & 59117 & 10.65 & - & Gain & - & - & - & Yes & Yes & - & - & Yes & - & - \\
\hline 2 & ClinVar & 59116 & 10.64 & - & Gain & - & - & - & Yes* & - & - & - & $?$ & - & - \\
\hline 3 & ClinVar & 59115 & 2.39 & - & Gain & - & - & - & - & Yes & - & - & - & - & - \\
\hline 4 & DECIPHER & 257554 & 0.91 & M & Gain & $\mathrm{No}^{* *}$ & 1 & - & - & Yes & - & - & - & Yes & - \\
\hline 5 & DECIPHER & 262506 & 2.51 & $\mathrm{~F}$ & Gain & Yes & 1 & Yes & Yes & Yes & Yes & - & Yes & Yes & - \\
\hline 6 & DECIPHER & 269407 & 3.57 & M & Gain & Yes & 1 & Yes & - & - & - & - & Yes & - & - \\
\hline 7 & DECIPHER & 274058 & 10.64 & $\mathrm{~F}$ & Gain & Yes & 1 & Yes & - & Yes & - & - & Yes & - & Yes \\
\hline 8 & DECIPHER & 275426 & 7.78 & $\mathrm{~F}$ & Gain & Yes & 1 & - & Yes & Yes & Yes & - & Yes & - & - \\
\hline 9 & DECIPHER & 282304 & 2 & $\mathrm{~F}$ & Gain & - & 2 & - & Yes & - & - & - & Yes & - & - \\
\hline 10 & DECIPHER & 282364 & 2.72 & $\mathrm{~F}$ & Gain & Yes & 1 & Yes & - & - & - & - & Yes & Yes & - \\
\hline 11 & DECIPHER & 328426 & 1.16 & $\mathrm{~F}$ & Gain & Yes & 1 & Yes & - & - & - & - & Yes & - & - \\
\hline
\end{tabular}

\begin{tabular}{|c|c|c|c|c|c|c|c|c|c|c|c|c|c|c|c|c|c|c|c|c|}
\hline & Literature & \multicolumn{2}{|c|}{ Patient } & \multicolumn{2}{|c|}{ Size (Mb) } & Sex & \multicolumn{2}{|c|}{ Type of variant } & \multicolumn{2}{|c|}{ De novo } & \multicolumn{2}{|c|}{ No CNVs } & ID & DD & Seizures & Hypotonia & ASD & Dysm & Learning difficulties & Behavioral problems \\
\hline 12 & Dorn et al. ${ }^{13}$ & [1] & & 15.7 & & M & Gain & & - & & 1 & & Yes & Yes & Yes & - & - & Yes & - & - \\
\hline 13 & Dorn et al. ${ }^{13}$ & [2] & & 15.7 & & $\mathrm{~F}$ & Gain & & - & & 1 & & Yes & - & Yes & - & - & Yes & - & - \\
\hline 14 & Carvalheira et al. ${ }^{11}$ & [1] & & 10.6 & & $\mathrm{~F}$ & Gain & & Yes & & 1 & & Yes & Yes & Yes & - & - & Yes & Yes & - \\
\hline 15 & Wang et al. ${ }^{12}$ & [1] & & 1.22 & & - & Gain & & - & & 1 & & - & - & Yes & - & - & - & - & - \\
\hline 16 & Wang et al. ${ }^{12}$ & [5] & & 1.22 & & - & Gain & & - & & 1 & & - & - & Yes & - & - & - & - & - \\
\hline \multirow[t]{2}{*}{17} & Wang et al. ${ }^{12}$ & [7] & & 1.22 & & - & Gain & & - & & 1 & & - & - & Yes & - & - & - & - & - \\
\hline & GRIN2D pathogenic & & Pat & & Muta & & Sex & Effect & & De $n$ & & No CNVs & & DD & Seizures & Hypotonia & ASD & Dysm & $\begin{array}{l}\text { Learning } \\
\text { difficulties }\end{array}$ & $\begin{array}{l}\text { Behavioral } \\
\text { problems }\end{array}$ \\
\hline 18 & Li et al. ${ }^{2}$ & & [1] & & $\begin{array}{l}\text { p. } \\
\text { Val66 }\end{array}$ & & & Gain of func & & Yes & & - & & Yes & Yes & Yes & - & Yes & Yes & - \\
\hline 19 & Li et al. ${ }^{2}$ & & [2] & & $\begin{array}{l}\text { p. } \\
\text { Val66 }\end{array}$ & & & Gain of func & & Yes & & - & & Yes & Yes & Yes & - & - & Yes & - \\
\hline
\end{tabular}

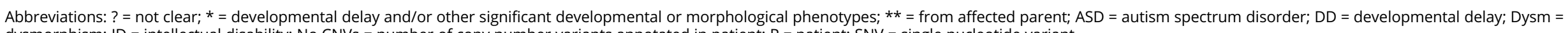
dysmorphism; ID = intellectual disability; No CNVs = number of copy number variants annotated in patient; P = patient; SNV = single nucleotide variant. 
Figure Genomic and facial overview of the microduplications overlapping the GRIN2D gene found in the retrieved patients

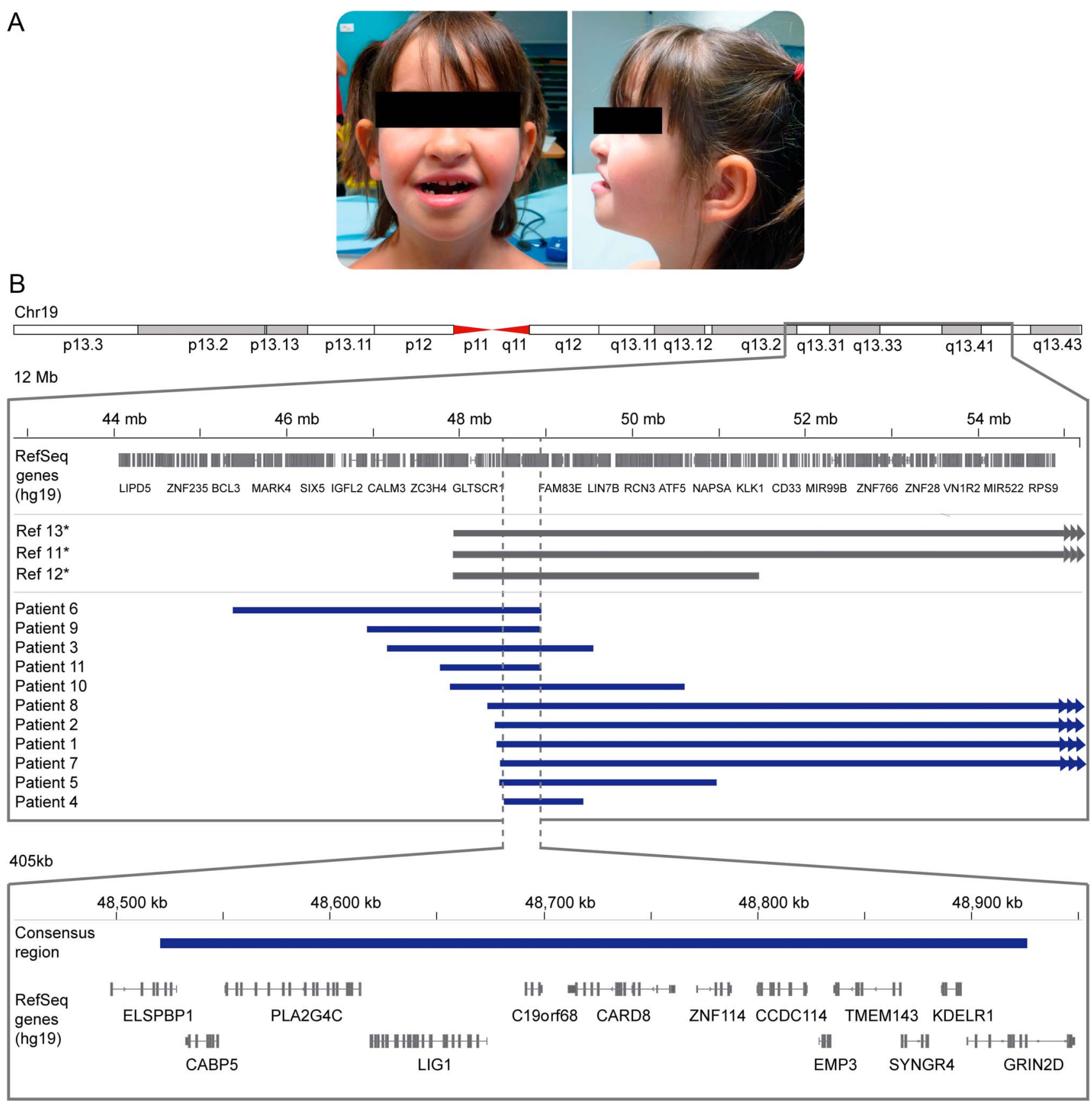

(A) Clinical anteroposterior facial photograph of patient 10 depicting characteristic facial features. (B) Thirteen patients were identified with GRIN2D duplications at the 19q13.33 locus. Blue horizontal bars represent the respective microduplication size and breakpoints according to GRCh37/hg19 human genome reference in a 12-Mb genomic window. Gray horizontal bars represent the respective microduplication reported in the study by Dorn et al. ${ }^{13}$ Carvalheira et al. ${ }^{11}$ and Wang et al. ${ }^{12}$ in which no exact copy number variant boundaries are specified $(*)$. Microduplications larger than the depicted genomic interval are shown with arrows at boundaries (patients 1,2, 7, and 8). Bottom panel: The consensus duplicated region of the 12 patients is depicted in the blue horizontal bar in a 405-kb window. Thirteen RefSeq genes are located in this region.

genes. All $11 \mathrm{CNVs}$ were highly heterogeneous in their size (average $=4.99 \mathrm{Mb} ; \mathrm{SD}=4.05 \mathrm{Mb}$ ) and breakpoint distribution (encompassing from $\mathrm{Chr} 19: 45.38 \mathrm{Mb}-59.09 \mathrm{Mb}$, Hg19) (table 1).

To identify additional CNVs absent in ClinVar and/or DECIPHER databases, we screened the literature and retrieved 3 additional studies, including 6 patients with duplications at the $19 \mathrm{q} 13.33$ locus. ${ }^{11-13}$ All of these patients had seizures. Three patients carried CNVs of $1.22 \mathrm{Mb}$ size, whereas the remaining 3 duplications were $>10 \mathrm{Mb}$. Patients affected by the large CNVs were, in addition to seizures, also affected by other NDDs including ID and dysmorphism. 
Of interest, the 2 independent patients with the p.Val667lle mutation on GRIN2D featured similar NDDs including DD, dysmorphism, seizures, and muscular hypotonia (table 1).

Overall, the consensus duplicated region was determined to be located within the coordinates 48,520,809 bp-48,926,006 $\mathrm{bp}$, with a final size of $405 \mathrm{~kb}$. This is consistent with previous reports. ${ }^{11-13}$ The consensus region overlapped 13 RefSeq genes (figure, B) that were further examined for brain expression, the presence of CNVs overlapping these genes in control cohorts, and variation intolerance (table 2). Four genes persisted above all available filters, namely, the caspase recruitment domain family member 8 (CARD8), the chromosome 19 open reading frame 68 (C19orf68), the KDEL endoplasmic reticulum protein retention receptor 1 (KDELR1), and the glutamate ionotropic receptor NMDA type subunit 2D (GRIN2D). In our view, these 4 genes represent the most promising candidates.

We also searched for noncoding brain-specific functional elements within the consensus region. A total of 291 were found overlapping $9.87 \%$ of the consensus region $(40,019$ $\mathrm{bp})$. Within the consensus regions of the duplications, the density of noncoding elements was not significantly higher than that outside of chromosome 19.

\section{Discussion}

Here, we report on 11 patients with duplications at a potential novel disease locus within 19q13.33. Several lines of evidence support the hypothesis that duplications at this locus are associated with NDDs: (1) duplications at this locus are virtually absent in healthy individuals from the general population ${ }^{8}$; (2) all of the identified duplications with parental information arose de novo with the exception of patient 4, which according to DECIPHER was inherited from an affected parent with a similar phenotype (DECIPHER entry 257554); (3) none of the patients carried additional likely pathogenic CNVs; and (4) all duplications covered multiple plausible disease candidate genes.

The NDDs observed in the 11 patients were characterized by dysmorphism as the most prominent feature, followed by ID and seizures (table 1). Our observations are in agreement with previous reports. ${ }^{11-13}$ Although, 1 example ${ }^{12}$ focused exclusively on seizures, we cannot rule out that other NDDs were actually present in those patients. Similarly, we acknowledge that DD, behavioral problems, and learning difficulties may be subject to interobserver variability to some extent. In this regard, future clinical studies of $19 \mathrm{q} 13.33$ duplication carriers need to be conducted to draw detailed and robust genotypephenotype conclusions. Since previous reports from the

Table 2 Consensus region gene annotation and candidate gene filtering

\begin{tabular}{|c|c|c|c|c|c|c|c|c|c|c|}
\hline Transcipt ID & chrom & cdsStart & cdsEnd & Gene & $\begin{array}{l}\text { Size } \\
(\mathrm{pb})\end{array}$ & $\begin{array}{l}\text { Brain } \\
\text { expressed? }\end{array}$ & $\begin{array}{l}\text { DGV } \\
\text { [clean] } \\
\text { CNVs not } \\
\text { present in } \\
\text { controls? }\end{array}$ & $\begin{array}{l}\text { ExAC LoF } \\
\text { Intolerance? }\end{array}$ & $\begin{array}{l}\text { PCG } \\
\text { Browser } \\
\text { CNV not } \\
\text { present in } \\
\text { controls? }\end{array}$ & Total \\
\hline NM_022142 & chr19 & $48,511,924$ & $48,525,584$ & ELSPBP1 & 13,660 & No & Yes & No & Yes & $2 / 4$ \\
\hline NM_019855 & chr19 & $48,533,813$ & $48,547,179$ & CABP5 & 13,366 & No & Yes & No & Yes & $2 / 4$ \\
\hline NM_001159322 & chr19 & $48,551,599$ & $48,613,772$ & PLA2G4C & 62,173 & Yes & No & Yes & Yes & $3 / 4$ \\
\hline NM_001320971 & chr19 & $48,618,905$ & $48,668,823$ & LIG1 & 49,918 & Yes & Yes & Yes & No & $3 / 4$ \\
\hline NM_199341 & chr19 & $48,675,059$ & $48,700,084$ & C19orf68 & 25,025 & Yes & Yes & NA & Yes & $3 / 3$ \\
\hline NM_014959 & chr19 & $48,714,966$ & $48,744,277$ & CARD8 & 29,311 & Yes & Yes & Yes & Yes & $4 / 4$ \\
\hline NM_153608 & chr19 & $48,783,056$ & $48,790,135$ & ZNF114 & 7,079 & No & Yes & No & Yes & $2 / 4$ \\
\hline NM_144577 & chr19 & $48,800,232$ & $48,822,028$ & CCDC114 & 21,796 & Yes & Yes & No & Yes & $3 / 4$ \\
\hline NM_001313905 & chr19 & $48,830,101$ & $48,833,727$ & EMP3 & 3,626 & Yes & Yes & No & Yes & $3 / 4$ \\
\hline NM_018273 & chr19 & $48,836,475$ & $48,867,177$ & TMEM143 & 30,702 & Yes & No & Yes & Yes & $3 / 4$ \\
\hline NM_012451 & chr19 & $48,869,099$ & $48,879,575$ & SYNGR4 & 10,476 & No & Yes & Yes & Yes & $3 / 4$ \\
\hline NM_006801 & chr19 & $48,886,549$ & $48,894,615$ & KDELR1 & 8,066 & Yes & Yes & Yes & Yes & $4 / 4$ \\
\hline NM_000836 & chr19 & $48,901,649$ & $48,947,194$ & GRIN2D & 45,545 & Yes & Yes & Yes & Yes & $4 / 4$ \\
\hline \multicolumn{11}{|c|}{$\begin{array}{l}\text { a'Brain-expressed genes from Uddin et al. }{ }^{6} \\
{ }^{6} \text { DGV curated CNV control map from Zarrei et al. } \\
{ }^{7} \text { ExAC LoF Intolerant genes from Lek et al. } \\
\text { dPCG Control CNVs from Marshall et al. } .^{8} \\
\text { Bold genes are positive in all applicable filters and are }\end{array}$} \\
\hline
\end{tabular}


literature were based on low-resolution cytogenetic methods, ${ }^{13}$ identification of the underlying disease gene was not possible. Here, we show that by integration of multiple CNVs data sets from public repositories, we are able to narrow down the disease-associated genomic sequence to a few candidate genes at the 19q13.33 locus (figure).

Our included data sets do not allow estimation of 19q13.33 duplication frequency. However, the absence of 19q13.33 duplications in CNVs databases of the general population and the presence of only a few variant carrying patients in diagnostic CNVs databases with heterogeneous breakpoints indicate that 19q13.33 duplications are extremely rare (table 2 ).

All 11 of the identified patient CNVs shared a genomic interval of $405 \mathrm{~kb}$, which includes 4 genes with genetic, population and biological support of disease association. These included CARD8, C19orf68, KDELR1, and GRIN2D. For CARD8, C19orf68, and KDELR1, no association with NDDs has been reported in the literature to date. Although we cannot rule out that brain-specific noncoding elements at 19 q13.33 could be involved in the development of NDDs, GRIN2D represents a plausible candidate gene for association with NDDs. GRIN2D, encoding the NMDA receptor subunit GluN2D, is highly expressed prenatally and after birth before progressively declining through adulthood. ${ }^{14}$ It is possible that GRIN2D microduplications may predispose to disease susceptibility in a dose-dependent manner by enhancing GluN2D expression during development, thereby influencing the NMDA receptor composition, which might provoke changes in neuronal networks, thus contributing to hyperexcitability and neurologic diseases. ${ }^{15}$ Besides CNVs, the GRIN2D gene is also depleted due to negative selection of missense and truncating variants in the general population, supporting the GRIN2D association with disease. ${ }^{8}$ In agreement, 2 recently identified GRIN2D single nucleotide variants also lead functionally to a gain-of-function mutation in 2 patients with similar outcomes ${ }^{2}$ (table 1). Beyond the potential diagnostic relevance, our identification of GRIN2D as a possible new NDD gene has a potential clinical application, since memantine, a low-affinity therapeutic NMDA channel blocker, selectively blocks extrasynaptic NMDA receptors that are likely to contain GluN2C/2D subunits. ${ }^{16}$ This might especially be relevant for patients with gain-offunction mutations or microduplications. ${ }^{2}$

\section{Author contributions}

Eduardo Pérez-Palma: analysis and interpretation of data and wrote the manuscript. Elmo Saarentaus: analysis and interpretation of clinical data. Giancarlo V. De Ferrari: critical revision of the manuscript for intellectual content. Marie Ravoet, Giancarlo V. De Ferrari, Peter Nürnberg, and Bertrand Isidor: clinical and critical revision of the manuscript for intellectual content. Bernd A. Neubauer: drafting of the manuscript and critical revision of the manuscript for intellectual content. Dennis Lal: study concept and design, analysis and interpretation of data, and wrote the manuscript.

\section{Acknowledgment}

The authors thank all the clinicians, patients, and their families. This study makes use of data generated by the DECIPHER community. A full list of centers who contributed to the generation of the data is available from http://decipher.sanger.ac.uk and via email from decipher@ sanger.ac.uk. Funding for the project was provided by the Wellcome Trust.

\section{Study funding}

Eduardo Pérez-Palma was supported by the Chilean Fondo Nacional de Desarrollo Científico y Tecnológico (FONDECYT) regular grant number 1140353 to Giancarlo V. De Ferrari. Dennis Lal received funds from the German Academic Exchange Service (DAAD), grant number 57073880. Bernd A. Neubauer received funding from the Deutsche Forschungsgemeinschaft (Ne 416/5-1).

\section{Disclosure}

E. Pérez-Palma has received research support from Fondo Nacional de Ciencia y Tecnología (FONDECYT), Chile. E. Saarentaus has received research support from the Institute for Molecular Medicine Finland (FIMM) and Svenska Studiefonden. M. Ravoet has been involved in clinical procedures/imaging studies at the Center of Human Genetics, Cliniques Universitaires St-Luc (10\%), 2016. G.V. De Ferrari has received research support from Fondo Nacional de Ciencia y Tecnología (FONDECYT), Chile, and CONICYT. Chile. P. Nuernberg is a founder, CEO, and shareholder of ATLAS Biolabs GmbH (ATLAS Biolabs GmbH is a service provider for genomic analyses). B. Isidor reports no disclosures. B. Neubauer has served on the scientific advisory boards of and has received travel funding/speaker honoraria from Eisai, Bial, and UCB Pharma; has served on the editorial board of Neuropediatrics; and has received research support from DFG 416/5-1 (German national funding agency). D. Lal reports no disclosures. Full disclosure form information provided by the authors is available with the full text of this article at Neurology.org/NG.

Received August 17, 2017. Accepted in final form September 11, 2017.

\section{References}

1. van Zundert B, Yoshii A, Constantine-Paton M. Receptor compartmentalization and trafficking at glutamate synapses: a developmental proposal. Trends Neurosci 2004; 27:428-437.

2. Li D, Yuan H, Ortiz-Gonzalez XR, et al. GRIN2D recurrent de novo dominant mutation causes a severe epileptic encephalopathy treatable with NMDA receptor channel blockers. Am J Hum Genet 2016;99:802-816.

3. Firth HV, Richards SM, Bevan AP, et al. DECIPHER: database of chromosomal imbalance and phenotype in humans using Ensembl resources. Am J Hum Genet 2009;84:524-533.

4. Landrum MJ, Lee JM, Benson M, et al. ClinVar: public archive of interpretations of clinically relevant variants. Nucleic Acids Res 2016;44:D862-D868.

5. Battle DE. Diagnostic and statistical manual of mental disorders (DSM). Codas 2013; 25:191-192.

6. Uddin M, Tammimies K, Pellecchia G, et al. Brain-expressed exons under purifying selection are enriched for de novo mutations in autism spectrum disorder. Nat Genet 2014;46:742-747.

7. Zarrei M, MacDonald JR, Merico D, Scherer SW. A copy number variation map of the human genome. Nat Rev Genet 2015;16:172-183.

8. Lek M, Karczewski KJ, Minikel EV, et al. Analysis of protein-coding genetic variation in 60,706 humans. Nature 2016;536:285-291. 
9. Marshall CR, Howrigan DP, Merico D, et al. Contribution of copy number variants to schizophrenia from a genome-wide study of 41,321 subjects. Nat Genet. 2017;49: 27-35.

10. Lu Q, Powles RL, Wang $\mathrm{Q}, \mathrm{He}$ BJ, Zhao $\mathrm{H}$. Integrative tissue-specific functional annotations in the human genome provide novel insights on many complex traits and improve signal prioritization in genome wide association studies. PLoS Genet 2016; 12:e1005947.

11. Carvalheira G, Oliveira MM, Takeno S, Lima FT, Meloni VA, Melaragno MI. $19 \mathrm{q} 13.33->$ qter trisomy in a girl with intellectual impairment and seizures. Meta gene 2014;2:799-806
12. Wang D, Li X, Jia S, et al. Copy number variants associated with epilepsy from gene expression microarrays. J Clin Neurosci 2015;22:1907-1910.

13. Dorn T, Riegel M, Schinzel A, Siegel AM, Kramer G. Epilepsy and trisomy 19qdifferent seizure patterns in a brother and a sister. Epilepsy Res 2001;47:119-126.

14. Paoletti P, Bellone C, Zhou Q. NMDA receptor subunit diversity: impact on receptor properties, synaptic plasticity and disease. Nat Rev Neurosci 2013;14:383-400.

15. Lemke JR, Lal D, Reinthaler EM, et al. Mutations in GRIN2A cause idiopathic focal epilepsy with rolandic spikes. Nat Genet 2013;45:1067-1072.

16. Wu YN, Johnson SW. Memantine selectively blocks extrasynaptic NMDA receptor in rat substantia nigra dopamine neurons. Brain Res 2015;1603:1-7. 


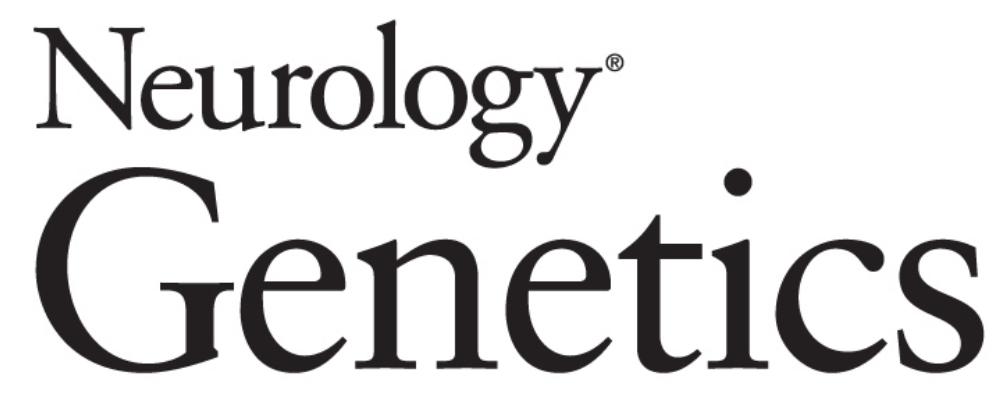

\section{Duplications at 19q13.33 in patients with neurodevelopmental disorders}

Eduardo Pérez-Palma, Elmo Saarentaus, Marie Ravoet, et al.

Neurol Genet 2018;4;

DOI 10.1212/NXG.000000000000210

This information is current as of January 29, 2018

\section{Updated Information \&} Services

\section{References}

Subspecialty Collections

Permissions \& Licensing

\section{Reprints}

including high resolution figures, can be found at: http://ng.neurology.org/content/4/1/e210.full.html

This article cites 16 articles, 0 of which you can access for free at: http://ng.neurology.org/content/4/1/e210.full.html\#\#ref-list-1

This article, along with others on similar topics, appears in the following collection(s):

All Epilepsy/Seizures

http://ng.neurology.org//cgi/collection/all_epilepsy_seizures

Developmental disorders

http://ng.neurology.org//cgi/collection/developmental_disorders

Ion channel gene defects

http://ng.neurology.org//cgi/collection/ion_channel_gene_defects

Information about reproducing this article in parts (figures,tables) or in its entirety can be found online at:

http://ng.neurology.org/misc/about.xhtml\#permissions

Information about ordering reprints can be found online:

http://ng.neurology.org/misc/addir.xhtml\#reprintsus

Neurol Genet is an official journal of the American Academy of Neurology. Published since April 2015, it is an open-access, online-only, continuous publication journal. Copyright Copyright @ 2018 The Author(s). Published by Wolters Kluwer Health, Inc. on behalf of the American Academy of Neurology. All rights reserved. Online ISSN: 2376-7839.

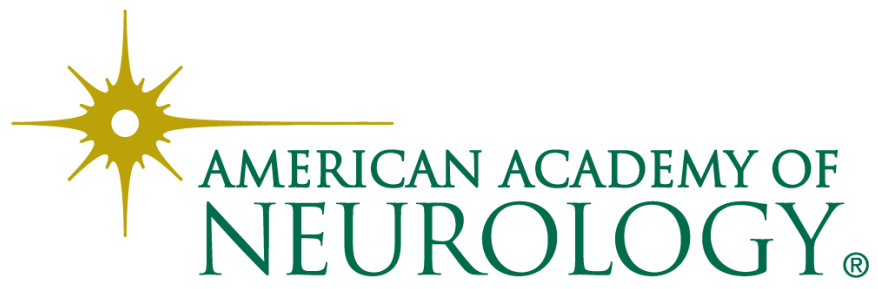

